\title{
THE MODERATING ROLE OF RELIGIOSITY ON THE RELATIONSHIP BETWEEN SATISFACTION WITH WORK-LIFE BALANCE AND JOB SATISFACTION
}

\author{
Jahanvash Karim1 \\ Institute of Management Sciences, University of Balochistan, \\ Quetta \\ Zainab Bibi2 \\ Institute of Management Sciences, University of Balochistan, \\ Quetta \\ Faisal Aftab3 \\ Bahria University, Islamabad
}

\begin{abstract}
Purpose: - The impact of work-life balance on work-related outcomes has been the focus of much attention by researchers in organizational behavior and psychology. The aim of this study was to extend this literature by examining the potential moderating effect of religiosity on the relationship between satisfaction with work-life balance and job satisfaction. Methodology/Sample: - Data from The European Social Survey (ESS Round 6 Edition 1.2) provided the basis for this study $(N=21621)$.

Findings: - Results suggested that satisfaction with work-life balance was positively related to job satisfaction and religiosity fostered the effect of satisfaction with work-life balance on job satisfaction.

Practical Implications:- The findings of this study suggest that religiosity holds relevance to a variety of work outcomes. Faith and involvement in religious activities act as a personal resource, making individuals more resilient to cope with the challenges arising from worklife imbalance.
\end{abstract}

Keywords: Religiosity, Job Satisfaction, Work-Life Balance, Moderation

* The material presented by the author does not necessarily portray the viewpoint of the editors and the management of the Institute of Business \& Technology (IBT)

1 Jahanvash Karim

2 Zainab Bibi

:vash@hotmail.com

:znb2005@hotmail.com

3 Faisal Aftab

:faftab@bahria.edu.com

(C) IBT-JBS is published by the Institute of Business and Technology (IBT).

Main Ibrahim Hydri Road, Korangi Creek, Karachi-75190, Pakistan. 


\section{INTRODUCTION}

The construct of work-life balance has attracted much research attention in recent years (Wu, Rusyidi, Claiborne, \& McCarthy, 2013). It has been defined as "the relationship between the institutional and culture times and spaces of work and nonwork in societies where income is predominantly generated and distributed through labour markets"( Felstead, Jewson, Phizacklea, \& Walters, 2002, p. 56). Empirical investigations support strong associations between work-life balance and job satisfaction, one of the most commonly studied job attitudes in organizational behavior (e.g, Carlson, Grzywacz, \&Zivnuska, 2009; Ollier-Malaterre, 2010; Saltzstein, Ting, \&Saltzstein, 2001; Wu et al., 2013) . Likewise, various studies have well-documented that employees' religious beliefs and practices- defined as the "strength of one's connection to or conviction for their religion" (King \& Williamson, 2010, p.175) - tend to be related positively to job satisfaction (e.g., King \& Williamson, 2010; Kutcher, Bragger, Rodriguez-Srednicki, \& Masco, 2010; Parasuraman, Zummuto,\&Outcalt, 1984; SikorskaSimmons, 2005). Although previous researches have tested and confirmed the independent effects of work-life balance and religiosity on job satisfaction, the interactive (joint) effects of work-life balance and religiosity on job satisfaction is still an untouched issue.

\subsection{Theory and hypothesis}

The Hobfoll's (1989) "Conservation of Resources (COR)" model offers an appropriate framework for understanding the work-life balance research (Grandey\&Cropanzano, 1999). According to the COR model, individuals seek to create a world that will provide them pleasure. In this nexus, to achieve a state of pleasure, individuals strive to acquire, maintain, foster, and protect their valued resources used to meet the demands of the work and non-work environments, including objects (e.g., transportation, foods, clothes, homes), personal dispositions, socioemotional or psychosocial resources, (e.g., self-efficacy, social support, psychological resilience, or self-esteem), conditions (e.g., marital status, job experience), or energies (e.g., effort, knowledge, money, and time). Psychological stress occurs when there is loss of resources, a threat of a loss of resources, or a lack of expected gain in a resource following the investment of resources. When confronted with stress, individuals strive to enrich resource or offset resource loss by investing resources they possess, what Hobfoll (1989) called 'resource investment'.

The COR model proposes that employees strive to conform to the demands of both work and non-work environments as a function of resource replenishment and investment. Work-life imbalance may trigger various stress reactions (or negative states of being) (e.g., anxiety, depression, or job dissatisfaction), because resources are often lost in the process of juggling between various roles (Grandey\&Cropanzano, 1999). In other words, resource loss in one domain (e.g., work) may lead to depletion of resources in the other domains (e.g., life). For instance, dealing with personal life demands reduces employees' energy and time at work, which in turn cause negative outcomes in the work domain (e.g., burnout leading to decreased job satisfaction) (Gao, 
Shi, Niu, \& Wang, 2013).

In the context of COR theory, individual differences are treated as (personal) resources and differences in levels of personal resources may help to reduce (or buffer) the negative consequences of stressful work or life events (such as work-life imbalance) on individuals or offset the negative effects of resource loss. For example, individuals with high self-esteem have high energy reserves as well as a reserve of self-worth and self-confidence which, in turn, may help in replenishing resources that are lost in attempting to balance work and family lives. Thus, abundance and investment of (personal) resources leads to positive employee outcomes (e.g., job satisfaction) (Hobfoll, 2001). In this study, we propose religiosity as an important personal resource that mightmoderate the relationship between work-life balance and job satisfaction.

Religiosity, an individual difference variable (a personality trait or disposition), is considered a personal resource in the context of COR (e.g., Byrne, Morton, \&Dahling, 2011; King \& Williamson, 2010; Skrzypinska\& Saucier, 2006), that may interact with other variables to produce outcomes. Religious beliefs and practices, as a personal resource, offer personal comfort, provide valuable sources of social support, influence one's self-perceptions (e.g., self-esteem, self-efficacy, ) in a positive way, and promote constructive coping(Byrne et al., 2011; Ellison and \& Levin, 1998). As mentioned earlier, work-life imbalance leads to stress in all domains simultaneously because resources (e.g., energy) are lost in juggling between work and non-work domains. Consistent with COR theory, religious people hold rich reservoir of personal (socioemotional and psychosocial) resources, which enable them to replenish resources lost in balancing their work and life roles and domains simultaneously (e.g., time and energy) and to offset the detrimental outcomes arising from work-life imbalance. Thus, we expect that religiosity would strengthen the positive effect of satisfaction with worklife balance on job satisfaction. Figure 1 depicts our proposed research model.

Hypothesis: Religiosity moderates the relationship between satisfaction with work-life balance and job satisfaction, such that the positive impact of satisfaction with work-life balance on job satisfaction will be higher among individuals who report higher levels of religiosity.

Various studies have indicated that job satisfaction is associated with gender, age, satisfaction with income, and total hours worked (Clark \& Oswald, 1996; Doering, Rhodes, \& Schuster, 1983; Hodson, 1989; Nanda \& Browne, 1977). Therefore, we controlled for these variables in the analyses. (See Figure 1 in Appendix)

\section{METHODS}

\subsection{Data}

Data from the sixth round (edition 1.2 released on 13.01.2014) of the European Social Survey (ESS) are analyzed. The ESS questionnaire includes questions on satisfaction with work-life balance, religiosity, and job satisfaction. 23 countries are 
covered in the sixth round (Belgium, Bulgaria, Switzerland, Cyprus, Czech Republic, Germany, Denmark, Estonia, Spain, United Kingdom, Ireland, Israel, Iceland, Netherlands, Norway, Poland, Portugal, Russian Federation, Sweden, Slovenia, Slovakia, Kosovo). A list wise deletion, based on main constructs of the present study, produced a sample of 21621 (51.4\% Males; 48.6 Females; Mage= 43.16; SD = 12.52).

\subsection{Measures}

Job satisfaction: A single-item measure of job satisfaction was used in the present analyses: "How satisfied with job" (coded on a metric from 0 ["Extremely dissatisfied"] to10 ["Extremely satisfied"]).

Satisfaction with work-life balance: A single-item measure of optimism was used in the present analyses: "How satisfied with balance between time on job and time on other aspects" (coded on a metric from 0 ["Extremely dissatisfied"] to10 ["Extremely satisfied"]).

Religiosity: The ESS asks two questions about extrinsic religiosity: "How often attend religious services apart from special occasions?" and "How often pray apart from at religious services", with a 7-point scale ranging from $1=$ "Every day" to $7=$ "Never". The items were reverse-coded. Analyses utilized composite scores of two items so that a higher score reflects higher level of religiosity.

Satisfaction with income: A single-item measure was used to measure satisfaction with income in the present analyses: "Feeling about household's income nowadays" (coded on a metric from 1 ["Living comfortably on present income"] to4 ["Very difficultly on present income"]).The items were reverse-coded so that a higher score reflects higher level of satisfaction with income.

Number of hours worked per week: A single item measure was used to measures total number of hours worked per week: "Total contracted hours per week in main job overtime excluded".

Statistical analyses: Analyses were performed using SPSS software (version 16 of 2007; IBM Corporation, New York). Hypothesis was tested using hierarchical multiple regression analysis. We entered control variables in step one, and satisfaction with work-life balance and religiosity in step two. In step three, we added the interaction term of satisfaction with work-life balance and religiosity. In line with Aiken and West (1991) recommendations, main variables (satisfaction with work-life balance and religiosity) were centered. We used $\ddot{A} F$ statistics to assess each hierarchical multiple regression step. We used variance inflation factor (VIF)criteria to assess the multicollinerity between variables. 


\section{RESULTS}

Table 1 provides the descriptive statistics and bivariate correlations among the study variables. As the table shows, satisfaction with work-life balance and religiosity had a significant positive correlation with job satisfaction.

Hierarchical multiple regression results (Table 2) showed that control variables (gender, age, satisfaction with income, and hours worked) explained $7.8 \%$ of the variance in job satisfaction $\left(R^{2}=.078, p<.01\right)$. The addition of satisfaction with work-life balance and religiosity in step 2 increased the explained variance significantly for job satisfaction $\left(R^{2}=.286, p<.01\right)$. In step 3 , the interaction term (satisfaction with worklife balance $\mathrm{x}$ religiosity) was significant $(B=.014, p<.01)$, explaining an additional.01\% of the variance in job satisfaction $\left(R^{2}=.001, p<.01\right)$. (See Table $1 \& 2$ in Appendix)

Examination of the interaction plot showed an enhancing effect that as satisfaction with work-life balance and religiosity increased, satisfaction with job increased (Figure 2). At low satisfaction with work-life balance, levels of job satisfaction were similar for individuals with low or high levels of satisfaction with work-life balance. Individuals with high levels of religiosity and satisfaction with work-life balance were more satisfied with their jobs, supporting our hypothesis. (See Figure 2 in Appendix)

\section{DISCUSSION}

Most of the previous research on work-life balance has focused on the direct relationship between work-life balance and its outcomes (e.g, Carlson, Grzywacz, \&Zivnuska, 2009; Ollier-Malaterre, 2010), there is still not much evidence of important moderator variables. To fill in this gap, we employed Hobfoll's (1989) COR theory to further our understanding of how the religiosity and satisfaction with work-life balanceinteract to influence job satisfaction.

In this cross-sectional study of 21623, predominantly European employees, we found that both satisfaction with work-life balance and religiosity significantly contributed to job satisfaction. Moreover, we found that religiosity moderated the relationship between satisfaction with work-life balance and job satisfaction, such that the positive impact of satisfaction with work-life balance on job satisfaction was higher among individuals who reported higher levels of religiosity. This is the first study, to our knowledge, to report moderating effects of religiosity on the work-life balance-job satisfaction relationship.

We tested the relationships among job satisfaction, religiosity and satisfaction with work-life balance from a COR perspective. Hobfoll's COR theory (1989) provides an explanatory framework and important insights on how work-life balance affects important work-related outcomes. According to this theory, employees strive to accumulate, protect, replenish, and invest personally valued resources to strike a balance between work and non-work domains (Grandey\&Cropanzano, 1999). Abundance and investment of personal resources replenish employees' resources, lost in the process 
of managing the requirements of work and non-work responsibilities, consequently leading to positive employees' outcomes. Conversely, individuals with fewer personal resources are more vulnerable to resource loss. Any decrease in resources would create a negative spiral, which in turn, may lead to future loss. Faith and involvement in religious activities act as a personal resource, making individuals more resilient to cope with the challenges arising from work-life imbalance.

Religious individuals have higher levels of psychological resources (e.g., selfesteem, self-efficacy, internal locus of control) (Byrne et al., 2011), which, in turn, help them (a) to balance their work and personal lives and; (2) to invest these resources to offset the deleterious effects of work-life imbalance (if any) on job-related outcomes. In other words, inability to invest resources (due to low reserves of psychological resources) in response to distressful situations, arising from work-life imbalance, leads to job dissatisfaction. Religiosity serves as a protective factor against the development of negative job-related outcomes in the context of role conflicts arising between employees' work and non-work demands.

Although the above mechanism is the one we favor to explain the role of religiosity in the context of work-life balance, other plausible explanations exists. First, religiosity may influence job satisfaction through psychological detachment from work, which is considered as a personal resource (Moreno-Jiménez et al., 2009). It is defined as a "state of mind during non-work time characterized by the absence of job-related activities and thoughts" (Sonnentag, Kuttler, \& Fritz, 2010, p. 356). According to previous researches, disconnecting from work can act as a personal resource to offset the negative effects of work-life imbalance on work-related outcomes (Etzion, Eden, \& Lapidot, 1998; Moreno-Jiménez et al., 2009). Religious practices such as reading a holy book, praying, or attending religious services may help in psychologically detaching from work, which, in turn positively influence work-related attitudes or behaviors.

Second, according to Fredrickson (2002), religious practices cultivate positive emotions (such as joy, serenity, gratitude, and hope), which, "in turn broaden people's mindsets, making them more creative and integrative in their thinking, and build and replenish critical personal and social resources, such as resilience, optimism, and social support" (p. 211). Thus, experiences of positive emotions build enduring psychological resources allowing individuals to replenish resources and invest these in an attempt to gain future resources (such as job satisfaction).।

Third, positive associations between religious involvement and perceived social support have been well-documented (e.g., Koeing, 1998). Social support, in turn, serves to buffer the deleterious impact of work-life imbalance, provide coping resources, and help employees adapt to stressful environments. According to Brummelhuis, Oosterwaal, and Bakker (2012), "social support intervenes in the depleting effects of stressors on outcomes by adding or replenishing personal resources... Social support isthought to help employees balance work and family roles because it gives them additional time, energy, and fulfillment" (p. 381). Thus, religiosity through social support provides enough personal resources to employees to effectively cope with their work and life 
demands, thereby attenuating the effects of work-life imbalance on work-related outcomes.

\section{LIMITATIONS AND FUTURE DIRECTIONS}

There are some limitations to the present study. First, although this research employed an explicit measure of religiosity, an implicit measure of religiosity might yield different results. Future research should utilize implicit measures of religiosity to replicate the findings of this study. Second, satisfaction with work-life balance and job satisfaction were measured with single-item measures rather than scales of all possible dimensions. Assessing the constructs by employing multi-dimensional measures would provide much information. Third, the present study was cross-sectional in nature, which precluded establishing causal statements. Future studies should employ longitudinal designs to understand the causal links between variables. Fourth, self-report measures of the constructs are subject to various sources of measurement errors (e.g., common method variance). It would be ideal if objective measures of constructs were employed in future researches. Fifth, the results of the present study are limited to the scope of work-related outcomes examined. Satisfaction with work-life balance could be associated with several other outcomes, such as organizational citizenship behavior, counterproductive work behavior, or job performance (Allen, Herst, Bruck, \& Sutton, 2000). Therefore, it is suggested that, understanding the moderating role of the religiosity in the relationship between work-life balance and other outcomes would contribute to current work-life balance literature. Sixth, the significant interactive effect of work-life balance and religiosity on job satisfaction revealed to be very low $\left(\ddot{\mathrm{A}} R^{2}=.01 \%, p<.01\right)$. This indicates that some more variables (e.g., intrinsic religiosity) need to be included in the analyses. Finally, in this study, we employed hierarchical multiple regression analysis. Future studies could employ other statistical methods such as Structural Equation Modeling or Partial Least Squares to test the moderating role of religiosity.

\section{REFERENCES}

Aiken, L. S., \& West, S. G. (1991). Multiple regression: Testing and interpreting interactions. Newbury Park: Sage.

Allen, T., Herst, D., Bruck, C., \& Sutton, M. (2000). Consequences associated with work-to-family conflict: A review and agenda for future research. Journal of Occupational Health Psychology, 5, 278-308.

Brummelhuis, L. L., Oosterwaal, A., \& Bakker, A. B. (2012). Managing Family Demands in Teams: The Role of Social Support at Work. Group \& Organization Management, 37(3) 376-403.

Byrne, C. J., Morton, D. M., \&Dahling, J. J. (2011). Spirituality, religion, and emotional labor in the workplace. Journal of Management, Spirituality and Religion, 8(4), 299-315. 
Carlson, D. S., Grzywacz, J. G., \&Zivnuska, S. (2009). Is work-family balance more than conflict and enrichment? Human Relations, 62, 1459-1486.

Clark, A. E., Oswald, A. J. (1996). Satisfaction and comparison income. Journal of Public Economics, 61(3), 359-381.

Doering, M., Rhodes, S. R. \& Schuster, M. (1983). The Aging Worker. Beverly Hills, CA: Sage.

Etzion, D., Eden, D., \& Lapidot, Y. (1998). Relief from job stressors and burnout: Reserve service as a respite. Journal of Applied Psychology, 83, 577-585.

Ellison, C. G., \& Levin, J. S. (1998). The Religion-health connection: Evidence, theory, and future directions. Health Education \& Behavior, 25, 700-720.

Felstead, A., Jewson, N., Phizacklea, A., \& Walters, S. (2002). Opportunities to work at home in the context of work-life balance. Human Resource Management Journal, 12, 54-56.

Fredrickson, B.L. (2002). How does religion benefit health and well-being? Are positive emotions active ingredients? Psychological Inquiry, 13, 209-213.

Gao, Y., Shi, J., Niu, Q., \& Wang, L. (2013). Work-family conflict and job satisfaction: Emotional intelligence as a moderator. Stress Health, 29(3), 222-228.

Grandey, A., \&Cropanzano, R. (1999). The conservation of resources model applied to work-family conflict and strain. Journal of Vocational Behavior, 54, 350370.

Hobfoll, S. E. (1989). Conservation of resources: A new attempt at conceptualizing stress. American Psychologist, 44(3), 513-524.

Hobfoll, S.E. (2001). The influence of culture, community, and the nested self in the stress process: Advancing conservation of resources theory. Applied Psychology: An International Review, 50, 337-370.

Hodson, R. (1989). Gender differences in job satisfaction: Why aren't women more dissatisfied? The Sociological Quarterly, 30(3), 385-399.

King, J. E., \& Williamson, J. O. (2010). Workplace religious expression, religiosity and job satisfaction: Clarifying a relationship. Journal of Management, Spirituality and Religion, 2(2), 173-198.

Koenig, H. G. (1998). Handbook of religion and mental health. San Diego, CA: Academic Press. 
Kutcher, E. J., Bragger, J. D., Rodriguez-Srednicki, O., \& Masco, J. L. (2010). The role of religiosity in stress, job attitudes, and organizational citizenship behavior. Journal of Business Ethics, 95, 319-337.

Moreno-Jiménez, B., Mayo, M., Sanz-Vergel, A. I., Geurts, S., Rodríguez-Muñoz, A. \&Garrosa, E. (2009). Effects of Work-Family conflict on employees' wellbeing: The moderating role of recovery strategies. Journal of Occupational Health Psychology, 14, 427-440.

Nanda, R., \& Browne, J. J. (1977). Hours of work, job satisfaction and productivity. Public Productivity Review, 2(3), 46-56.

Ollier-Malaterre, A. (2010). Contributions of work-life and resilience initiatives to theindividual/organization relationship. Human Relations, 63, 41-62.

Parasuramana, S. Zammuto, R.F. \&Outcalt, D. (1984). On the role of work/nonwork involvement in influencing job and nonjob attitudes. Paper presented at the Fourth International Symposium on Forecasting, London, England.

Saltzstein, A. L., Ting, Y., \&Saltzstein, G. H. (2001). Work-family balance and job satisfaction: The impact of family-friendly policies on attitudes of federal government employees. Public Administration Review, 61, 452-467.

Sikorska-Simmons, E. (2005). Religiosity and work-related attitudes among paraprofessional and professional staff in assisted living. Journal of Religion, Spirituality \& Aging, 18, 65-82.

Skrzypinska, K., \& Saucier, G. (2006). Spiritual but not religious? Evidence for two independent dispositions. Journal of Personality, 74(5), 1257-1292.

Sonnentag, S., Kuttler, I. \& Fritz, C. (2010). Job stressors, emotional exhaustion, and need for recovery: A multi-source study on the benefits of psychological detachment. ÊJournal of Vocational Behavior, $\hat{E} 76(3), 355-365$.

SPSS Inc. (2007). SPSS for Windows, Version 16.0. Chicago: SPSS Inc.

Wu, L., Rusyidi, B., Claiborne, N., \& McCarthy, M. L. (2013). Relationships between work-life balance and job-related factors among child welfare workers. Children and Youth Services Review, 35, 1447-1454. 


\section{Appendix}

Figure 1: The moderating effect of religiosity on the relationship between satisfaction with work-life balance and job satisfaction.

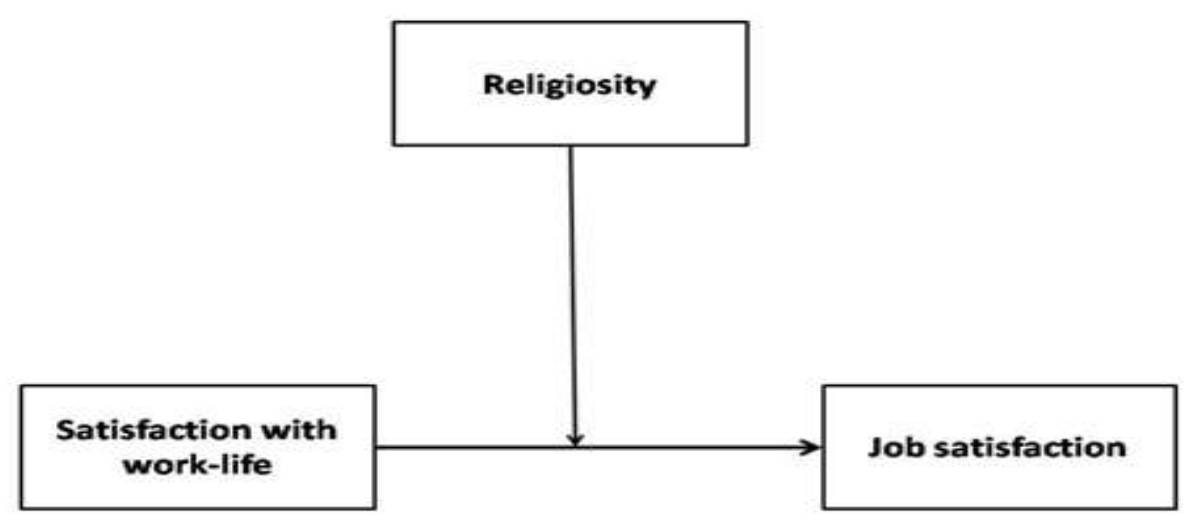

Table 1: Descriptive statistics and bivariate correlations among the study variables.

\begin{tabular}{lrrrrrrr}
\hline & 1 & 2 & 3 & 4 & 5 & 6 & 7 \\
\hline 1. Gender & & & & & & & \\
2. Age & .01 & & & & & & \\
3. Satisfaction with income & $-.06^{* *}$ & $.025^{* *}$ & & & & & \\
4. Total hours worked (per week) & $-.23^{* *}$ & .008 & $-.057^{* *}$ & & & & \\
5. Job satisfaction & -.01 & $.079^{* *}$ & $.279^{* *}$ & $-.025^{* *}$ & & & \\
6. Work-life balance & .001 & $.087^{* *}$ & $.203^{* *}$ & $-.157^{* *}$ & $.504^{* *}$ & & \\
7. Religiosity & $.11^{* *}$ & $.087^{* *}$ & $-.108^{* *}$ & -.008 & .010 & $.017^{*}$ & \\
N & 21621 & 21586 & 21502 & 20505 & 21621 & 21621 & 21621 \\
Mean & 1.49 & 43.16 & 3.05 & 37.07 & 7.50 & 6.75 & 2.67 \\
Standard Deviation & .50 & 12.52 & .81 & 10.97 & 2.01 & 2.19 & 1.69 \\
Skewness & .057 & .040 & -.59 & -.06 & -1.09 & -.60 & .76 \\
Kurtosis & -1.99 & -.711 & -.13 & 7.07 & 1.32 & -.01 & -.68 \\
\hline Note. Gender was coded '1' for
\end{tabular}

Note. Gender was coded ' 1 ' for men and ' 2 ' for women

${ }^{*} p<.05, " p<.01$. 
Table 2: Results of hierarchical regression analyses predicting job satisfaction

\begin{tabular}{|c|c|c|c|c|c|c|c|c|c|}
\hline & Beta & $\beta$ & SE & $\mathrm{t}$ & $\mathrm{R}^{2}$ & $\Delta \mathrm{R}^{2}$ & $\Delta \mathrm{F}$ & VIF & $\begin{array}{l}\text { Semi- } \\
\text { partial } r\end{array}$ \\
\hline \multicolumn{10}{|l|}{$\begin{array}{l}\text { Step 1. Control } \\
\text { variables }\end{array}$} \\
\hline Gender & .008 & .030 & .028 & 1.10 & .078 & .078 & $429.94^{* *}$ & 1.07 & .01 \\
\hline Age & .070 & .011 & .001 & $10.28^{* *}$ & & & & 1.00 & .07 \\
\hline $\begin{array}{l}\text { Satisfaction with } \\
\text { income }\end{array}$ & .266 & .660 & .017 & $38.88^{* *}$ & & & & 1.01 & .26 \\
\hline $\begin{array}{l}\text { Total hours worked } \\
\text { (per week) }\end{array}$ & -.007 & $.00 \overline{1}$ & .002 & -1.054 & & & & 2.59 & -.010 \\
\hline \multicolumn{10}{|l|}{ Step 2. Main effects } \\
\hline Work-life balance & .471 & .428 & .006 & $76.81^{* *}$ & .286 & .208 & $2967.13^{* *}$ & 1.07 & .45 \\
\hline Religiosity & .021 & .024 & .007 & $3.44^{* *}$ & & & & 1.03 & .020 \\
\hline \multicolumn{10}{|l|}{ Step 3. Interaction } \\
\hline $\begin{array}{l}\text { Work-life balance X } \\
\text { religiosity }\end{array}$ & .025 & .014 & .003 & $4.18^{* *}$ & .287 & .001 & $17.50^{* *}$ & 1.00 & .025 \\
\hline
\end{tabular}

Figure 2: Interaction between satisfaction with work-life balance and religiosity on job satisfaction

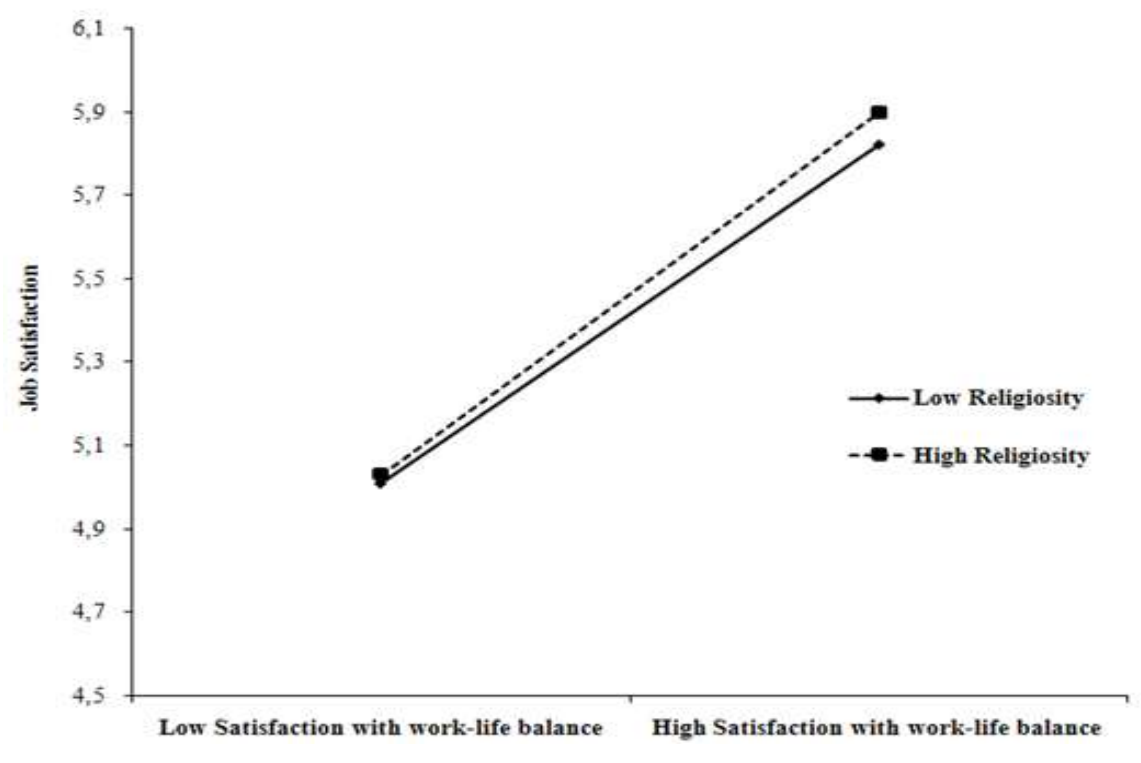

